\title{
Actual, ideal, and expected relatedness with parents across and within cultures
}

\author{
E. OLCAY IMAMOĞLU ${ }^{1 *}$ AND \\ ZAHIDE KARAKITAPOĞLU-AYGÜN ${ }^{2 * *}$ \\ ${ }^{1}$ Middle East Technical University, Turkey \\ ${ }^{2}$ Bilkent University, Turkey
}

\begin{abstract}
Differences in actual, ideal, and expected relatedness with mothers and fathers were explored across two cultural groups (i.e., university students from the U.S. and Turkey) in Study 1, and across two socioeconomic status (SES) groups (i.e., high school students from the upper and lower SES in Turkey) in Study 2. In both studies associations of perceived relatedness with individualistic and collectivistic value orientations as well as with self-construal types were also explored. Results indicated cultural groups to be quite similar in actual relatedness, but to differ in expected and ideal relatedness, with Turks reporting more relatedness. In Turkey, lower SES adolescents reported more relatedness in ideal and actual conditions than upper SES adolescents, while they did not differ in expected relatedness. Results involving self-types and value orientations pointed to both cross-cultural similarities and within-cultural diversity in relatedness. Theoretical implications of the differential impact of culture, SES, self-construals, and value orientations on actual, ideal, and expected relatedness are discussed. Copyright (C) 2006 John Wiley \& Sons, Ltd.
\end{abstract}

Cultures tend to influence our self-definitions and relationships with others through cultural beliefs about what is desirable, referred to as the cultural syndromes (Triandis, 1995). Among these syndromes, individualism-collectivism (I-C) differentiation is the most studied one in predicting self-development and social behavior. The cross-cultural literature within the I-C framework indicates that there are cultural differences in how related or separated people construe themselves. Accordingly, people from the more collectivist cultures are characterized as having more related, overlapping and interdependent selves whereas those from the individualist cultures are characterized as being more separate and independent from others (Markus \& Kitayama, 1991; Triandis, 1995).

On the other hand, attachment theorists have suggested relatedness to parents or primary caregivers to be a universal phenomenon (Ainsworth, 1972; Bowlby, 1988). However, other researchers have suggested that the biological predisposition for relatedness may be similar across individualist and collectivist cultures, but they tend to pass through the cultural lenses of individuation and

*Correspondence to: E. Olcay Imamoğlu, Department of Psychology, Middle East Technical University, Ankara 06531, Turkey. E-mail: eolcay@metu.edu.tr

**Correspondence to: Zahide Karakitapoğlu-Aygün, Faculty of Business Administration, 06899 Bilkent Ankara, Turkey.

E-mail: zkaygun@bilkent.edu.tr 
accommodation, respectively (Rothbaum, Pott, Azuma, Miyake, \& Weisz, 2000). They further noted that while the collectivist cultures tend to be characterized by extreme indulgence of the caregiver and complete dependence of the child, the individualist cultures tend to be characterized by the tension between desires for both closeness and separation from the caregiver. Thus, collectivist cultures have been assumed to be generally characterized by greater relatedness than the individualist cultures. In this vein, particularly the most individualistic U.S. culture (as well as the individualistic tradition in mainstream psychology) has been criticized for neglecting or 'underappreciating' the importance of relatedness (Baumeister \& Leary, 1994), and instead putting too much emphasis on 'self-contained' individualism (Sampson, 1988); for instance, Bellah, Madsen, Sullivan, and Tipton (1985) have criticized parent-child relations in the U.S. by noting that 'For highly individuated Americans, there is something anomalous about the relation between parents and children, for the biologically normal dependence of children on adults is perceived as morally abnormal' (p. 82).

On the other hand, some recent studies suggested that relationality should not be considered as equivalent to collectivism but that individualistic, collectivistic, and relational dimensions of the self tend to be orthogonal to each other (Kashima et al., 1995; Oyserman, Coon, \& Kemmelmeier, 2002). For instance, Kashima et al. demonstrated that the relational dimension portrays, not cultural but, gender differences. Other researchers further differentiated between the value orientations of individualism, collectivism, and familism (i.e., referring to being oriented toward the welfare of one's own, one's larger community, and one's immediate and extended family, respectively), and suggested that individuals' orientations to their families need to be considered as distinct from their larger communities (Gaines et al., 1997).

As might be inferred from the above review, the role of relationality in a cultural framework does not seem to be very clear. On the one hand, relatedness is considered as a basic dimension of selfconstruals that differentiates between collectivistic and individualistic cultures (e.g., Markus \& Kitayama, 1991; Triandis, 1995); on the other hand, it has been demonstrated to be a separate dimension that is not pertinent or relevant to I-C differentiation but to gender (Kashima et al., 1995). In a similar vein, the individualist U.S. culture, on the one hand, has been criticized for neglecting the importance of relationality (e.g., Baumeister \& Leary, 1994; Sampson, 1988), on the other hand, relationality has been said to characterize the American type of interdependence, as distinct from the Eastern type of interdependence based on group memberships (Cross, Bacon, \& Morris, 2000). Furthermore, from the arguments of the attachment theorists one would expect relatedness, especially to parents, to be a universal phenomenon, although the particular styles of attachment may be different (Van Ijzendoorn \& Sagi, 1999). We aimed to shed light on some of these issues by exploring whether university students from Turkey and the U.S., categorized as collectivist and individualist societies, respectively (Hofstede, 1980), differ in the degree to which they construe themselves as related with their mothers and fathers.

There is further ambiguity in the literature regarding the exact role of culture on the type of relatedness perceived; for instance, when reference is made to perceiving the self as separate from or overlapping with others as a basic aspect of I-C or independence-interdependence (e.g., Markus \& Kitayama, 1991), are we to understand differences in actually perceived relatedness; or differences in normative expectations; or differences in what is considered as the ideal degree of relatedness in those cultures? In the present studies we aimed to tackle this issue by obtaining separate measures of actual, ideal, and expected degrees of relatedness, in line with Higgins' self-discrepancy theory (1987).

Self-discrepancy theory (Higgins, 1987) postulates three basic domains of the self: (a) the actual self refers to a person's representation of the attributes that he/she believes the person actually possesses. In the present study, the actual related self (or actual relatedness) refers to the degree to which individuals construe themselves as being 'separate from' or 'related to' their parents. (b) The ideal self refers to a person's representation of the attributes that the person would like to possess 
ideally (including hopes, wishes, or aspirations). In the present case, the ideal related self (or ideal relatedness) expresses the degree to which individuals would like to be related to their parents. Studying idealized degree of relatedness may shed light on the direction of future trends and hence its exploration may be especially important in rapidly changing societies such as Turkey. (c) The ought self refers to a person's representation of the attributes that the person should or ought to possess (as an obligation, duty, or responsibility). In the present study, this domain was assumed to be parallel to the expected related self (or expected relatedness), referring to individuals' perceptions of their parents' expectations regarding relatedness. In other words, it refers to social expectations or norms about the degree of inclusion of others in the self-concept in a culture and may be more likely to reflect normative differences across contexts.

Exploring relatedness in these three domains enabled us to address 'the question of where the seat of culture really is'. 'That is, if the actual lived experiences of individuals regarding relatedness were different across cultures, as is often assumed, then, we might expect differences in actual related selves. If cultures mainly function by influencing goals, wishes, aspirations, or values regarding relatedness, then we might expect differences in ideal related selves. However, cultural systems not only serve descriptive functions but also make normative claims that may be developed into obligations (D'Andrade, 1997). Hence, if cultures basically operate by having their impact on social norms, responsibilities, duties, or obligations regarding relationality, then, we might expect differences in expected relatedness.

Another issue we aimed to tackle in the present study concerns within-culture variability in relatedness with parents. Cultures often are assumed to be more homogeneous than they actually are; for example, as noted above, people from a relatively collectivistic culture are assumed to be more related than those from an individualistic one. However, individuals within a particular culture often tend to vary in the degree to which they internalize the culture's outlook. As Geertz (1973a, 1973b) noted, social relations depend on the interaction of cultural, social structural and personality systems. Thus, by considering within-cultural variation, we aimed to go beyond the tacit understanding which regards culture as a property of some social group and tried to further explore how relatedness with parents varies depending on socioeconomic-status (SES), self-construal types, and value orientations of individuals. In a similar vein, several investigators have referred to the need to capture the withinculture variability in self-construals (Bandura, 2001; Imamoğlu, 2003; Sinha \& Tripathi, 1994). For example, on the basis of the Balanced Integration and Differentiation (BID) model, Imamoğlu (1998, 2003) identified four self-construal types among Turkish university students. The present study also has utilized the four self-types suggested by the BID model, as explained later in the paper. In another related study, Imamoğlu and Karakitapoğlu-Aygün (2004) found that both Turkish and American university students with similar BID-based self-types showed similar value orientation patterns, pointing to both cross-cultural similarities and within-culture variation. In fact, differences in selfconstrual types seemed to have more impact on value orientations than cultural differences. Furthermore, SES-related differences in self-construals and values between Turkish adolescents appeared to be more pronounced than cross-cultural differences between Turkish and American university students. Those earlier findings point to the importance of exploring the within-culture variability in self-construals and values.

Thus, our aim in the present studies was to increase understanding of the role and significance of relatedness as a dimension of both cross and within-cultural differences. Specifically, first, we aimed to tackle the issue of how culture achieves its effect by studying actual, ideal, and expected degrees of relatedness in the Turkish and U.S. contexts. Secondly, we aimed to tackle the issue of within-culture variation in relatedness by exploring (a) the impact of general self-types; i.e., whether individuals with

\footnotetext{
${ }^{1}$ We are grateful to an anonymous reviewer for encouraging us to focus more keenly on this issue.
} 
different self-construal types, based on the BID model, tend to perceive their actual, ideal, and expected relatedness with parents differently within each culture, and show similar patterns of relatedness across cultures; (b) the impact of self-directed and other-directed value orientations implying individualistic and collectivistic outlooks; i.e., whether variations in individuals' I-C-related value orientations predict their perceptions of actual, ideal, and expected relatedness within each culture, and in a similar fashion across cultures; and (c) the impact of SES differences (upper, lower) in Turkey; i.e., whether individuals from different SES groups vary in their perceptions of actual, ideal, and expected degrees of relatedness. In the second study involving SES differences in Turkey, we also considered within-SES variation in relatedness involving the BID-related self-types and I-C-related value orientations.

Our expectations are considered further below in relation both to the first study involving Turkish and American university students as well as the second study involving cross-status differences among Turkish adolescents. However, first, the BID model, which, as noted above, has been used to specify different self-types, is briefly described below.

\section{DIFFERENT SELF-TYPES PROPOSED BY THE BID MODEL}

The BID model (Imamoğlu, 1995, 2003) assumes human beings to have basic psychological needs for both intrapersonal differentiation (i.e., a self-developmental tendency to actualize one's unique potentials and be effective) and for interpersonal integration (i.e., an interrelational tendency to be connected to others). The low and high ends of the latter orientation are labeled as separatedness and relatedness, respectively. The high end of the former orientation is referred to as individuation (i.e., becoming differentiated as a unique person with intrinsic referents, such as personal capabilities, inclinations, free will or willful consent), while the low end is referred to as normative patterning (i.e., becoming patterned in accordance with extrinsic referents, such as normative expectations and social control).

The combinations of these distinct and complementary intrapersonal differentiation and interpersonal integration orientations are suggested to give rise to four types of self-construals: i.e., separated-individuation, related-patterning (representing the most differentiated and the integrated types, respectively), separated-patterning and related individuation (representing the most unbalanced and balanced types, respectively). The model assumes that these different self-types tend to be similar across cultures in terms of their associations with psychological variables. Investigators who have used the BID scale, which is described later in the paper, have provided support for the model among Turkish, American, and Canadian samples (Gezici \& Güvenç, 2003; Güler, 2004; Imamoğlu, 1998, 2002, 2003; Imamoğlu \& Karakitapoğlu-Aygün, 2004; Kurt, 2002). Expectations concerning the BID-related self-types are considered below.

\section{STUDY 1: PERCEIVED RELATEDNESS WITH PARENTS IN TURKEY AND THE U.S.}

\section{Cultural Differences}

As noted above, the related literature indicates Turkey and the U.S. to differ on the I-C classification, the latter representing the most individualist culture, while Turkey representing a collectivist culture that is close to the midpoint on the I-C classification (Hofstede, 1980). Accordingly, the Turkish sociocultural context has been traditionally characterized by an emphasis on interpersonal relationships and close ties with family and relatives encouraging higher levels of relatedness than, for 
instance, the Swedes (Imamoğlu \& Imamoğlu, 1992; Imamoğlu, Küller, Imamoğlu, \& Küller, 1993). Although among the upper segments of the society there appears to be a trend to express more individuation in self-construals and value orientations, still relatedness seems to be retained (Imamoğlu, 1987, 2003; Imamoğlu \& Karakitapoğlu-Aygün, 2004; Karakitapoğlu-Aygün \& Imamoğlu, 2002). More importantly, when asked about their desired levels of relatedness, Turkish people consistently report favoring even more relatedness with family members and neighbors (Imamoğlu, 1987, 2002; Imamoğlu \& Imamoğlu, 1996).

On the other hand, in the related I-C literature, people from the individualistic American culture are generally characterized as being less related than those from the more collectivist Asian cultures (Triandis, Bontempo, Villareal, Asai, \& Lucca, 1988; Uleman, Rhee, Bardoliwalla, Semin, \& Toyama, 2000). For example, in terms of closeness with family and relatives, Turks were found to be closest, Euro-Americans more distant and Asian-Americans in between (Uleman et al., 2000).

Thus, on the basis of the I-C framework and the above-noted studies, Turkish respondents may be expected to report more relatedness with their parents than the Americans. However, as considered before, there seems to be some conflicting evidence regarding the role of relationality; for instance, as noted previously, Kashima et al. (1995) reported that relationality was not relevant to I-C differentiation but was orthogonal to it. On the other hand, regarding relationality in the U.S., other investigators (e.g., Cross et al., 2000; Oyserman et al., 2002) concluded that Americans tend to be relational in terms of being close to their families and groups, though not in terms of feeling obligated or duty-bound. For example, Cross et al. (2000) noted that people who have high levels of relational interdependent selves, characteristic of the American type of interdependent self, were more likely to rate their important relationships as close, to show more commitment to their relationships and to consider the needs of others in their decisions. Thus, those studies tend to provide evidence that conflicts with the expectations of the traditional I-C outlook. Furthermore, a recent study involving 16 cultures (including Turkey and U.S.A.) indicated that all countries showed close emotional bonds with mothers, fathers, and siblings, with only minor differences across cultural groups (Georgas et al., 2001). Other investigators have also concluded that patterns of emotional closeness do not differ systematically across cultures (Fijneman, Willemsen, \& Poortinga, 1996; Van den Heuvel \& Poortinga, 1999). Similarly, Imamoğlu and Karakitapoğlu-Aygün (2004) demonstrated that Turkish and American university students tend to be quite similar in terms of their interrelational orientations.

Thus, the above-noted studies seem to provide somewhat conflicting messages regarding relationality differences to be expected between Turkey and the U.S. As will be remembered, we aimed to get a clearer picture of cultural differences by obtaining specific measures of actual, ideal, and expected degrees of relatedness. Accordingly, on the basis of the recent evidence pointing to cross-cultural similarities in relationality (e.g., Georgas et al., 2001), we expected Turkish and American respondents to be quite similar in actual relatedness with parents. However, in view of their respective differences in collectivist and individualist traditions, which would be expected to provide different cultural syndromes (Triandis, 1995), we expected Turks to report more relatedness in terms of ideals and expectations than the Americans. In these predictions, our idea was that culture's impact on actual degree of relatedness with parents might be much less than that on social norms, rules, obligations, or the social 'expectations' as well as values, goals, aspirations or 'ideals'.

\section{Relatedness Differences Involving Self-Types and Value Orientations}

In both societies, we expected to find similar patterns of variability in relatedness depending on selftypes and value orientations of respondents. Specifically, regardless of culture, we generally expected the collectivistic value orientation to be positively associated with perceived relatedness (Triandis, 
1995), but the individualistic orientation to be either distinct (Kashima et al., 1995), or somewhat negatively associated, as suggested by the I-C framework. Again, regardless of culture, we expected respondents with related (i.e., both the related-individuated and related-patterned types) rather than separated self-construals to perceive themselves as more related with their parents. Since the BIDrelated self-types are assumed to reflect actual differences, we expected the impact of self-types to be mostly on actual relatedness. On the other hand, because values are considered as desirable guidelines (Rokeach, 1973; Schwartz, 1992), their impact might be mostly on ideal relatedness. That is, unlike the cross-cultural differences, which were expected to be significant for ideal and expected relationality, we expected respondents with different self-types or value orientations to show more diversity in actual and ideal relatedness compared to expected relatedness; i.e., since they live in the same culture, the expectations or social norms regarding relationality might presumably be more or less similar, regardless of self-types or value orientations. No culture-specific predictions were made regarding the associations between relatedness judgments and endorsement of I-C values apart from the general expectations noted above.

\section{Gender Differences}

Studies investigating self-conceptions indicated that gender-related expectations and social roles might play an important role in self-definitions. According to research conducted in the U.S. (Cross \& Madson, 1997; Gabriel \& Gardner, 1999; Gilligan, 1982; Lykes, 1985; Mellor, 1989; Olver, Aries, \& Batgos, 1989), generally, men are more likely to have less related and independent selves that emphasize personal agency, instrumentality, uniqueness and differentiation. Females, on the other hand, are more likely to have interdependent and relational self-construals emphasizing relatedness and embeddedness with others, and especially with their mothers (Jordan, 1997); for example, Gabriel and Gardner (1999) found that women describe themselves as more relational, have higher scores on relational self-construal, show more emotional experiences in association with relationships and pay more attention to information about relationships; men, on the other hand, were found to show a more separate and differentiated self than women, and more clear boundaries with others (Olver et al., 1989).

In a similar vein, in a series of studies investigating the self-descriptions of Turkish adolescents by using Twenty Statements Test, Sunar (1999) found that women attributed more importance to interpersonal characteristics and reported greater satisfaction with regard to these interpersonal attributes. In more recent studies, female university students were found to be both more related, and more individuated than males (Imamoğlu, 2002, 2003; Imamoğlu \& Karakitapoğlu-Aygün, 2004; Kurt, 2002). Thus, there is evidence that gendered socialization seems to encourage women toward a relational construal of self more than men. In the light of these findings, female respondents were expected to report more relatedness with their parents, and especially with their mothers, as compared to male ones in both cultural groups. Furthermore, because femininity generally is considered to imply relatedness, as noted above, female respondents might be expected to idealize relationality, especially with mothers, more than male respondents.

\section{Method}

\section{Participants}

Eight-hundred-sixty-three Turkish and American university students participated in the study, as explained below. 
American (U.S.A.) Sample A sample of 441 University of Michigan undergraduates (186 male, 255 female) taking introductory psychology courses participated in the study to fulfill a course requirement. The mean age of the sample was $18.88(S D=0.97)$, ranging from 18 to 24 . The sample was predominantly Euro-American, with $81 \%$ identifying as Euro-American, $9.3 \%$ as AsianAmerican, $5.7 \%$ as African-American, and $3.4 \%$ other. $^{2}$

Turkish Sample The Turkish sample consisted of 422 undergraduate students (185 male, 237 female; mean age 19.75, $S D=1.84$, range 17-25) from different departments of two universities in Ankara. In terms of parental education, most of the respondents were from middle and upper-middle SES families. ${ }^{3}$

The Turkish and the U.S. samples were generally comparable in terms of gender and age, but not in terms of parental education. The education level of the U.S. parents was somewhat higher than that of the Turkish sample (mean level of total years of education $=16.88, S D=2.52$ for the U.S. parents; and $\mathrm{M}=10.84, S D=3.97$ for Turkish parents). Therefore, as noted later, parental education was statistically controlled while investigating the cross-cultural differences.

\section{Measures and Procedure}

Questionnaires were group-administered to students together with other scales not considered in the present paper. The Turkish and English versions of the scales, checked through back translations, were used as described below. Two native speakers of English and Turkish also checked the scales for wording, accuracy, and clarity of items in both languages.

All respondents filled out the questionnaires in class. One-point bonus was given to the students for their participation, which was on a voluntary basis. The participants were assured that their responses would be anonymous and confidential.

Perceived Relatedness Scale A measure of perceived relatedness was developed by the authors for the present research purposes, based on a modification of Interpersonal Closeness Scale (Aron, Aron, \& Smollan, 1992; Aron, Aron, Tudor, \& Nelson 1991). Interpersonal Closeness Scale. Following Aron et al., relatedness with parents was defined as inclusion of the mother or the father in the self-concept. Relatedness was conceptualized in terms of perceived emotional closeness, similarity of thoughts, similarity of personality characteristics and relatedness (versus distinctness) of identity. High scores on the scale denote being more related.

The scale was administered in three different formats: actual, ideal and expected degrees of relatedness with parents. In the actual condition, degree of current emotional closeness and similarity with parents, and degree of perceived independence of identity from parents were asked. Examples are, 'Which of the drawings best describes your affective relationship with your mother/father?', 'To what extent are your father's/mother's and your own thoughts similar in general?', 'To what extent do you perceive yourself as an independent and distinct individual from your mother/father?' In the ideal condition, emotional closeness and similarity (in terms of thoughts and personality characteristics) that adolescents would like to have with their parents and the kind of individual they would like to be in terms of degree of independence were asked. Examples are; 'How would you wish your relationship

\footnotetext{
${ }^{2}$ The results of the analyses comparing Euro-American and other minority groups on the dependent variables indicated that groups, in general, did not differ from each other.

${ }^{3}$ No differences were observed between student groups from the two universities except that mean parental education of students from the Middle East Technical University $(M=11.73)$ was somewhat higher that of those from Hacettepe University $(M=9.61, p<0.001)$.
} 
with your mother/father to be?', 'To what extent would you wish your mother's/father's and your own thoughts to be similar?', 'To what extent do you wish to be an independent and distinct individual from your mother/father?'. With regard to expected relatedness with mothers and fathers, adolescents' opinions about their parents' expectations regarding the degree of relatedness in each domain were asked. Example questions are; 'In your opinion, how does your mother/father expect your relationship to be?', 'In your opinion, to what extent does your mother/father expect your thoughts to be similar to hers/his?', 'In your opinion to what extent does your mother/father expect you to be an independent and distinct individual from her/him?'. All the items were measured via the Venn-like diagrams (two circles-labeled 'me' and 'mom' or 'dad'-with increasing degrees of overlap) whose response options changed between 1 (no-overlap between circles) and 9 (total overlap between circles).

The reliability and validity of the scale were tested in a pilot study involving 125 Turkish university students. The respective Cronbach's alpha values in relation to mothers and fathers were 0.77 and 0.87 for actual, 0.75 and 0.83 for ideal, 0.80 and 0.82 for expected conditions. Moreover, validity checks with the question 'To what extent does your mother/father constitute an important part of your sense of who you are?' yielded moderate to high correlations (varying between 0.40 and 0.74 ) for different types of relatedness indicating good construct validity. (As can be seen in Table 2, in the present study, alpha values were also satisfactory for both cultural groups, as well as the SES groups of the second study).

Self-Directed or Individualistic and Other-Directed or Collectivistic Value Orientations In line with the related literature (e.g., Markus \& Kitayama, 1991), 14 values were selected from Schwartz Value Survey (1992) half of which represented self-directedness and the rest, other-directedness. Selfdirected values (i.e., freedom, creativity, independent, curious, capable, choosing own goals, and self-respect) represented an individualistic orientation of attending to the needs and goals of the self rather than the others and were mainly concerned with Schwartz et al.'s (2001) self-direction domain. On the other hand, other-directed values (i.e., honoring of parents and elders, obedient, helpful, devout, reciprocation of favors, respect for tradition, and family security) represented a collectivistic orientation of attending to the needs and wishes of others and were concerned with the conformity, benevolence, and traditionalism domains according to Schwartz et al. (2001).

Respondents rated the importance of each value as a guiding principle in their lives on a 5-point scale (1 'not important at all' and 5 'very important'). Separate factor analyses indicated the selfdirected/individualistic and other-directed/collectivistic values to be loaded under two separate factors for each cultural group (and SES group in the second study), except that in the analysis of the U.S. (and lower SES) data the weakest item loaded under both factors. For the Turkish university student sample, Cronbach's alpha values were 0.73 and 0.75 , and for the American sample 0.75 and 0.71 for individualistic and collectivistic value orientations, respectively.

Balanced Integration-Differentiation (BID) Scale This self-construal scale (Imamoğlu, 1998, 2003) consists of two subscales. The Self-Developmental Orientation subscale, consisting of 13 items, is concerned with intrapersonal differentiation toward individuation (i.e., relying on one's inner qualities and interests as a developmental frame of reference rather than accommodating oneself to a normative frame of reference). Sample items are: 'It is important for me that I develop my potential and characteristics and be a unique person' and the reverse-scored item of, 'I feel it is more important for everyone to behave in accordance with societal expectations rather than striving to develop his/her uniqueness.' The 16-item Interrelational Orientation measures tendencies and preferences for relatedness and connectedness with family and others. Sample items are: 'I emotionally feel very close to my family' and the reverse-scored item of, 'I feel emotionally alienated from my close environment.' Participants were asked to indicate their degree of agreement with the items using 
5-point scales ranging from 1 (not at all) to 5 (very). Cronbach's alpha values were reported to vary between 0.74 and 0.82 for the former and between 0.80 and 0.91 for the latter subscales in different studies (Gezici \& Güvenç, 2003; Güler, 2004; Imamoğlu, 1998, 2003; Kurt, 2002). In the present study, alpha values were 0.77 and 0.86 for the Turkish sample, and 0.71 and 0.86 for the American sample for self-developmental and interrelational orientations, respectively. Test-retest reliabilities of the subscales, over a period of three weeks, were found to be 0.85 and 0.84 , respectively (Güler, 2004). The scale was found to have good convergent and discriminant validity (Imamoğlu, 2002). Mean scores on these subscales are used to measure individuation and relatedness, respectively. As noted above, combinations of high and low scores on these two subscales (using medians as cutting points) yield four self-construal types; i.e., separated-individuated, related-patterned types representing the most differentiated and most integrated types, respectively; and separated-patterned and relatedindividuated types representing the most unbalanced and balanced types, respectively (for further explanation see Imamoğlu, 1998, 2003).

\section{Results}

First, in order to explore cross-cultural and gender differences in types of relatedness, a 2 (culture: Turkey, U.S.A.) $\times 2$ (gender: male, female) $\times 2$ (parent: mother, father) $\times 3$ (type of relatedness: actual, ideal, expected) analysis of covariance (ANCOVA) with repeated measures on the last two variables was conducted. Secondly, cross and within-culture differences involving self-types and value orientations were explored by separate multivariate analyses of covariance (MANCOVAs), using actual, ideal, and expected types of relatedness as dependent variables, as explained below. In all cross-cultural analyses, parental education was included as a covariate because there were some weak correlations between parental education and relatedness measures in our samples. Since sample sizes were large for both cultural groups, the more conservative 0.01 level of significance was accepted. In follow-up analyses, Tukey technique was used for within-subject effects and univariate analysis of covariance was used for between-subject effects. Moreover, in order to explore whether individualistic and collectivistic value orientations predict relatedness, separate regression analyses were conducted.

\section{Cross-Cultural Differences in Relatedness}

According to the ANCOVA analysis noted above, main effects involving culture, parent, and type of relatedness were significant, as shown in Table 1 . Accordingly, Turkish respondents $(M=6.08)$ endorsed more relatedness with their parents than the U.S. respondents $(M=5.55)$; participants reported greater relatedness with their mothers $(M=6.03)$ as compared to fathers $(M=5.60)$; and as for the type of relatedness, expected relatedness $(M=6.57)$ had the highest scores followed by ideal $(M=5.74)$ and then actual $(M=5.14)$ relatedness $(p<0.001)$.

However, these main effects were qualified by significant interactions as can be seen in Table 1 . First, culture by type of relatedness was significant. As shown in Table 2, the Turkish and American students did not differ significantly in the actual relatedness, but they did so in the ideal and expected relatedness ( $p<0.001$ in both analyses).

Moreover, as shown in Table 1, gender of the respondent by type of relatedness interaction was also found to be significant. Post-hoc analyses showed that women displayed significantly higher levels of 
Table 1. Significant ANCOVA and MANCOVA results involving cross-cultural data

\begin{tabular}{|c|c|c|c|c|}
\hline Source & $M S E$ & $d f$ & $F$ & $\eta^{2}$ \\
\hline \multicolumn{5}{|c|}{ Differences in relatedness across cultural groups ${ }^{\mathrm{a}}$} \\
\hline Culture & 5.98 & 1,825 & $31.27 * * *$ & 0.04 \\
\hline Parent & 2.04 & 1,825 & $34.97 * * *$ & 0.04 \\
\hline Relatedness Type & 0.93 & 2,1650 & $108.28 * * *$ & 0.12 \\
\hline Culture $\times$ Relatedness Type & 0.93 & 2,1650 & $27.74 * * *$ & 0.03 \\
\hline Gender $\times$ Relatedness Type & 0.93 & 2,1650 & $7.03 * * *$ & 0.01 \\
\hline Gender $\times$ Parent & 2.04 & 1,1825 & $26.88 * * *$ & 0.03 \\
\hline Gender $\times$ Parent $\times$ Relatedness Type & 0.56 & 2,1650 & $5.59 * *$ & 0.01 \\
\hline \multicolumn{5}{|c|}{ Differences in relatedness of participants with different self-types ${ }^{b}$} \\
\hline Self-Type & & 9, 1988 & $17.19 * * *$ & 0.06 \\
\hline Actual Relatedness & 1.26 & 3,819 & $49.17 * * *$ & 0.15 \\
\hline Ideal Relatedness & 1.19 & 3,819 & $35.08 * * *$ & 0.11 \\
\hline Expected Relatedness & 1.07 & 3,819 & $7.13 * * *$ & 0.03 \\
\hline Culture $\times$ Self-Type & & 9,1988 & $3.39 * * *$ & 0.01 \\
\hline Actual Relatedness & 1.26 & 3,819 & 1.35 & 0.01 \\
\hline Ideal Relatedness & 1.19 & 3,819 & 1.67 & 0.01 \\
\hline Expected Relatedness & 1.07 & 3,819 & 2.25 & 0.01 \\
\hline \multicolumn{5}{|c|}{ Differences in relatedness of respondents with different value orientations ${ }^{c}$} \\
\hline Collectivist Orientation & & 3,810 & $32.19 * * *$ & 0.11 \\
\hline Actual Relatedness & 1.37 & 1,812 & $73.53 * * *$ & 0.08 \\
\hline Ideal Relatedness & 1.21 & 1,812 & $92.97 * * *$ & 0.10 \\
\hline Expected Relatedness & 1.05 & 1,812 & $40.98 * * *$ & 0.05 \\
\hline
\end{tabular}

${ }^{\mathrm{a}} \mathrm{A} 2$ (Culture) $\times 2($ Gender $) \times 2$ (Parent) $\times 3$ (Relatedness type) ANCOVA (parental education as covariate) with repeated measures on the two last variables is involved.

${ }^{\mathrm{b}} \mathrm{A} 2$ (Culture) $\times 4$ (Self type) MANCOVA using relatedness types as dependent variables is involved. For culture effects involving relatedness types, see Table 2 .

${ }^{\mathrm{c}}$ A 2 (Culture) $\times 2$ (Collectivist Value Orientation) $\times 2$ (Individualist Value Orientation) MANCOVA using relatedness types as dependent variables is involved. For culture effects involving relatedness types, see Table 2.

$* p<0.05 ; * * p<0.01 ; * * * p<0.001$.

Table 2. Means, standard deviations, alpha and F values for relatedness with parents involving cultural and SES data

\begin{tabular}{|c|c|c|c|c|c|c|c|c|c|}
\hline \multirow[t]{2}{*}{ Culture $^{\mathrm{a}}$} & \multicolumn{3}{|c|}{ Turkey } & \multicolumn{3}{|c|}{ U.S.A. } & \multirow[b]{2}{*}{$F^{\mathrm{b}}$} & \multirow[b]{2}{*}{$M S E$} & \multirow[b]{2}{*}{$\eta^{2}$} \\
\hline & $\alpha$ & $M$ & $S D$ & $\alpha$ & $M$ & $S D$ & & & \\
\hline Actual Relatedness & 0.84 & 5.24 & 1.35 & 0.76 & 5.05 & 1.09 & 1.98 & 1.49 & 0.00 \\
\hline Ideal Relatedness & 0.81 & 6.00 & 1.22 & 0.83 & 5.48 & 1.11 & $2.92 * * *$ & 1.35 & 0.03 \\
\hline Expected Relatedness & 0.77 & 7.01 & 1.03 & 0.77 & 6.13 & 1.07 & $76.55 * * *$ & 1.10 & 0.09 \\
\hline \multirow[t]{2}{*}{ SES } & \multicolumn{3}{|c|}{ Upper SES } & \multicolumn{3}{|c|}{ Lower SES } & & & \\
\hline & $\alpha$ & $M$ & $S D$ & $\alpha$ & $M$ & $S D$ & $F^{\mathrm{c}}$ & $M S E$ & $\eta^{2}$ \\
\hline Actual Relatedness & 0.85 & 5.42 & 1.60 & 0.82 & 6.01 & 1.62 & $12.18 * * *$ & 2.59 & 0.03 \\
\hline Ideal Relatedness & 0.87 & 6.21 & 1.61 & 0.80 & 7.17 & 1.40 & $36.31 * * *$ & 2.27 & 0.10 \\
\hline Expected Relatedness & 0.78 & 7.25 & 1.16 & 0.79 & 7.38 & 1.36 & 0.42 & 1.61 & 0.00 \\
\hline
\end{tabular}

${ }^{\mathrm{a}}$ Means are corrected for parental education.

${ }^{\mathrm{b}}$ Degrees of freedom $=1$ and $828-831$.

${ }^{\mathrm{c}}$ Degrees of freedom $=1$ and $335-343$.

$* p<0.05 ; * * p<0.01 ; * * * p<0.001$. 
Table 3. Gender differences in relatedness with parents involving cultural and SES data

\begin{tabular}{|c|c|c|c|c|c|c|c|}
\hline \multirow[t]{2}{*}{ Culture $^{a}$} & \multicolumn{2}{|c|}{ Women } & \multicolumn{2}{|c|}{ Men } & \multirow[b]{2}{*}{$F^{\mathrm{b}}$} & \multirow[b]{2}{*}{$M S E$} & \multirow[b]{2}{*}{$\eta^{2}$} \\
\hline & $M$ & $S D$ & $M$ & $S D$ & & & \\
\hline Relatedness With Parents & 5.87 & 1.02 & 5.74 & 1.08 & 3.09 & 1.05 & 0.00 \\
\hline Actual Relatedness & 5.13 & 1.22 & 5.15 & 1.23 & 0.01 & 1.49 & 0.00 \\
\hline Ideal Relatedness & 5.85 & 1.15 & 5.62 & 1.26 & $8.37 * *$ & 1.37 & 0.01 \\
\hline Expected Relatedness & 6.63 & 1.14 & 6.51 & 1.22 & 3.35 & 1.20 & 0.00 \\
\hline Relatedness With Mothers & 6.18 & 1.08 & 5.85 & 1.14 & $20.32 * * *$ & 1.14 & 0.02 \\
\hline Actual Relatedness & 5.53 & 1.44 & 5.23 & 1.33 & $10.87 * * *$ & 1.94 & 0.01 \\
\hline Ideal Relatedness & 6.05 & 1.28 & 5.64 & 1.36 & $21.79 * * *$ & 1.63 & 0.03 \\
\hline Expected Relatedness & 7.01 & 1.17 & 6.74 & 1.32 & $10.90 * * *$ & 1.30 & 0.01 \\
\hline Relatedness With Fathers & 5.54 & 1.26 & 5.64 & 1.31 & 1.09 & 1.63 & 0.00 \\
\hline Actual Relatedness & 4.74 & 1.61 & 5.08 & 1.64 & $8.37 * *$ & 2.61 & 0.01 \\
\hline Ideal Relatedness & 5.66 & 1.35 & 5.60 & 1.49 & 0.52 & 1.98 & 0.00 \\
\hline Expected Relatedness & 6.26 & 1.44 & 6.28 & 1.41 & 0.02 & 1.91 & 0.00 \\
\hline \multirow[t]{2}{*}{ SES } & \multicolumn{2}{|c|}{ Women } & \multicolumn{2}{|c|}{ Men } & & & \\
\hline & $M$ & $S D$ & $M$ & $S D$ & $F^{\mathrm{c}}$ & $M S E$ & $\eta^{2}$ \\
\hline Relatedness With Parents & 6.67 & 1.33 & 6.48 & 1.26 & 1.71 & 1.69 & 0.00 \\
\hline Actual Relatedness & 5.71 & 1.73 & 5.72 & 1.52 & 0.40 & 2.68 & 0.00 \\
\hline Ideal Relatedness & 6.90 & 1.61 & 6.49 & 1.54 & 3.42 & 2.48 & 0.01 \\
\hline Expected Relatedness & 7.45 & 1.27 & 7.19 & 1.27 & 3.22 & 1.60 & 0.01 \\
\hline Relatedness With Mothers & 6.87 & 1.28 & 6.51 & 1.31 & $7.14 * *$ & 1.68 & 0.02 \\
\hline Actual Relatedness & 5.93 & 1.79 & 5.72 & 1.61 & 1.16 & 2.92 & 0.00 \\
\hline Ideal Relatedness & 7.05 & 1.64 & 6.45 & 1.65 & $11.17 * * *$ & 2.71 & 0.03 \\
\hline Expected Relatedness & 7.64 & 1.25 & 7.36 & 1.28 & $4.43 *$ & 1.60 & 0.01 \\
\hline Relatedness With Fathers & 6.50 & 1.66 & 6.42 & 1.51 & 0.08 & 2.53 & 0.00 \\
\hline Actual Relatedness & 5.48 & 2.18 & 5.73 & 1.94 & 2.96 & 4.28 & 0.01 \\
\hline Ideal Relatedness & 6.75 & 1.87 & 6.53 & 1.72 & 0.15 & 3.24 & 0.00 \\
\hline Expected Relatedness & 7.27 & 1.59 & 7.01 & 1.62 & 1.62 & 2.57 & 0.01 \\
\hline
\end{tabular}

${ }^{\mathrm{a}}$ Means are corrected for parental education.

${ }^{\mathrm{b}}$ Degrees of freedom $=1$ and $828-853$.

${ }^{\mathrm{c}}$ Degrees of freedom $=1$ and $339-351$.

$* p<0.05 ; * * p<0.01 ; * * * p<0.001$.

relatedness with their parents than men did only in the ideal condition (see Table 3). The differences between men and women in actual and expected relatedness with parents were not significant.

Furthermore, gender of the respondent by parent interaction was found to be significant (Table 1). There were no differences between males and females on perceived relatedness with fathers, but on relatedness with mothers to which females assigned higher scores than males (see Table 3).

Finally, type of relatedness by parent by gender of the respondent interaction was significant (Table 1). As can be seen in Table 3, in terms of relatedness with mothers, women reported higher scores than men in all three types of relatedness. On the other hand, the only significant difference between men and women in relatedness with fathers was found on the actual type, which was assigned higher scores by men than women $(p<0.01)$.

In the sections below, only the effects involving self-types or value orientations are considered. Since culture-related differences in types of relatedness have already been reported, they are not repeated. 
Table 4. Relatedness with parents according to self-types involving the cultural and SES groups

\begin{tabular}{|c|c|c|c|c|c|c|c|c|c|c|}
\hline \multirow[t]{2}{*}{ Culture $^{\mathrm{a}}$} & \multicolumn{2}{|c|}{$\begin{array}{l}\text { Separated- } \\
\text { Patterned }\end{array}$} & \multicolumn{2}{|c|}{$\begin{array}{l}\text { Separated- } \\
\text { Individuated }\end{array}$} & \multicolumn{2}{|c|}{$\begin{array}{l}\text { Related- } \\
\text { Patterned }\end{array}$} & \multicolumn{2}{|c|}{$\begin{array}{c}\text { Related- } \\
\text { Individuated }\end{array}$} & \multirow[b]{2}{*}{$F^{\mathrm{b}}$} & \multirow[b]{2}{*}{$\eta^{2}$} \\
\hline & $M$ & $S D$ & $M$ & $S D$ & $M$ & $S D$ & $M$ & $S D$ & & \\
\hline Actual Relatedness & $4.71_{\mathrm{a}}$ & 1.15 & $4.55_{\mathrm{a}}$ & 1.16 & $5.67_{\mathrm{b}}$ & 1.09 & $5.50_{\mathrm{b}}$ & 1.12 & $49.17 * * *$ & 0.15 \\
\hline Ideal Relatedness & $5.46_{a}$ & 1.21 & $5.23_{\mathrm{a}}$ & 1.21 & $6.23_{\mathrm{b}}$ & 1.13 & $5.97_{\mathrm{b}}$ & 1.08 & $35.08 * * *$ & 0.11 \\
\hline Expected Relatedness & $6.47_{\mathrm{ab}}$ & 1.21 & $6.32 \mathrm{a}$ & 1.27 & $6.75_{\mathrm{b}}$ & 1.08 & $6.69_{\mathrm{ab}}$ & 1.11 & $7.13 * * *$ & 0.03 \\
\hline SES & $M$ & $S D$ & $M$ & $S D$ & $M$ & $S D$ & $M$ & $S D$ & $F^{\mathrm{c}}$ & $\eta^{2}$ \\
\hline Actual Relatedness & $4.65_{\mathrm{a}}$ & 1.75 & $4.77_{\mathrm{a}}$ & 1.47 & $6.43_{\mathrm{b}}$ & 1.25 & $6.34_{b}$ & 1.30 & $34.10 * * *$ & 0.24 \\
\hline Ideal Relatedness & $6.02_{\mathrm{a}}$ & 1.71 & $6.23_{\mathrm{a}}$ & 1.70 & $7.18_{\mathrm{b}}$ & 1.23 & $7.13_{\mathrm{b}}$ & 1.26 & $14.02 * * *$ & 0.12 \\
\hline Expected Relatedness & $6.86_{a}$ & 1.47 & $7.05_{\mathrm{ab}}$ & 1.37 & $7.45_{b c}$ & 1.17 & $7.71_{\mathrm{c}}$ & 1.00 & $7.48 * * *$ & 0.07 \\
\hline
\end{tabular}

${ }^{\mathrm{a}}$ Means are corrected for parental education.

${ }^{\mathrm{b}}$ Degrees of freedom $=3$ and $819-845$.

${ }^{\mathrm{c}}$ Degrees of freedom $=3$ and $323-339$.

$* p<0.05 ; * * p<0.01 ; * * * p<0.001$.

Note: Means in the same row that do not share a common subscript are significantly different, at least, at the 0.05 level.

\section{Differences in Relatedness of Respondents with Different Self-Types across and within Cultures}

According to the 2 (culture: Turkey, U.S.A.) $\times 4$ (self type: separated-patterned, separated-individuated, related-patterned, related-individuated) MANCOVA analysis using actual, ideal, and expected relatedness as dependent variables, self-type main effect was found to be significant (see Table 1). As shown in Table 4, all the univariate effects were significant. Accordingly, students with related selfconstruals (i.e., related-patterned and related-individuated) reported more relatedness with their parents as compared to those with separated self-construals (i.e., separated-patterned and separatedindividuated) in all types of relatedness except for expected relatedness in which only the difference between the separated-individuated and related-patterned groups reached significance. As can be seen in Table 4, the impact of self-types was greatest on actual relatedness and least on expected relatedness with ideal relatedness being in between.

Although the multivariate culture by self-type interaction was found to be significant, none of the univariate effects reached significance (Table 1). As can be seen in Figure 1, the overall patterns of relatedness were strikingly similar in both cultures except for a trend for the separated-individuated Americans to be relatively less related than their Turkish counterparts.

\section{Differences in Relatedness of Respondents with Different Value Orientations across and within Cultures}

To explore whether individualistic and collectivistic value orientations predicted relatedness with parents, first, regression analyses were computed. Actual, ideal and expected relatedness measures (combined for mothers and fathers) were predicted by individualistic and collectivistic values after controlling for parental education. As shown in Table 5, collectivistic values positively predicted all types of relatedness with parents in both cultural groups. On the other hand, there was a trend for the individualistic values to negatively predict actual and expected relatedness with parents only in the U.S. context (as well as a weak trend for ideal relatedness to do so), whereas they appeared to be independent of relatedness in the Turkish context. 


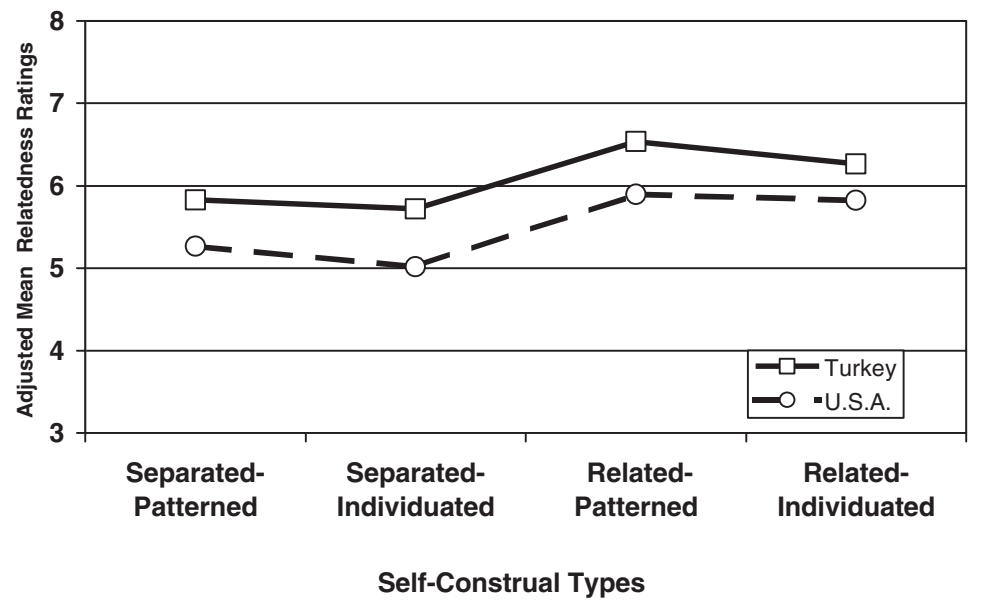

Figure 1. Adjusted (for parental education) mean relatedness scores of Turkish and American respondents with different self-types according to the BID model

Table 5. Predicting relatedness from individualistic and collectivistic values across cultural ${ }^{\mathrm{a}}$ and SES groups ${ }^{\mathrm{b}}$

\begin{tabular}{|c|c|c|c|c|}
\hline \multirow[t]{3}{*}{ Study 1} & \multicolumn{4}{|c|}{ Culture } \\
\hline & \multicolumn{2}{|c|}{ Turkey } & \multicolumn{2}{|c|}{ U.S.A. } \\
\hline & Individualistic & Collectivistic & Individualistic & Collectivistic \\
\hline Actual Relatedness & 0.00 & $0.38 * * *$ & $-0.14 * *$ & $0.33 * * *$ \\
\hline Ideal Relatedness & 0.01 & $0.43 * * *$ & $-0.11 *$ & $0.38 * * *$ \\
\hline Expected Relatedness & 0.07 & $0.21 * * *$ & $-0.14 * *$ & $0.34 * * *$ \\
\hline \multirow[t]{3}{*}{ Study 2} & \multicolumn{4}{|c|}{ SES (Turkey) } \\
\hline & \multicolumn{2}{|c|}{ Upper } & \multicolumn{2}{|c|}{ Lower } \\
\hline & Individualistic & Collectivistic & Individualistic & Collectivistic \\
\hline Actual Relatedness & -0.12 & $0.44 * * *$ & -0.02 & $0.37 * * *$ \\
\hline Ideal Relatedness & -0.14 & $0.56 * * *$ & -0.09 & $0.43 * * *$ \\
\hline Expected Relatedness & -0.05 & $0.23 * *$ & 0.05 & $0.40 * * *$ \\
\hline
\end{tabular}

${ }^{a}$ Parental education was controlled (entered in the first step).

${ }^{\mathrm{b}}$ Standardized Beta Coefficients are reported.

$* p<0.05 ; * * p<0.01 ; * * * p<0.001$.

To further explore whether the impact of individualistic-collectivistic value orientations on relatedness with parents differed across cultures, high and low individualist and collectivist groups were created by using medians of value orientations as cutting points; then, a 2 (culture: Turkey, U.S.A.) $\times 2$ (individualist value orientation: low, high) $\times 2$ (collectivist value orientation: low, high) MANCOVA was conducted using actual, ideal and expected relatedness as dependent variables. As shown in Table 1, the multivariate and univariate effects of collectivist value orientation were significant. As would be expected from the regression results shown in Table 5, those effects indicated that 
the more collectivistic respondents reported more relatedness than those less so. As shown in Table 1, the impact of collectivist value orientation seemed to be highest on ideal relatedness; then on actual relatedness; and lowest on expected relatedness. Furthermore, the collectivist orientation effect appeared to be independent of both culture and the individualist orientation.

\section{Discussion}

As expected, Turkish respondents generally reported more relatedness with their parents than the Americans. However, consistent differences were obtained in terms of actual, ideal, and expected types of relatedness across and within cultures. First, groups were similar in that all respondents perceived more relatedness in expected than in actual relatedness while their ideal selves were in between. Regarding differences across cultures, Turks differed from the Americans mostly in terms of expected relatedness, and to a lesser degree in terms of ideal relatedness; however, the groups did not differ from each other in terms of their reports of actual relatedness with parents. As considered later in the General Discussion, these findings have important implications for our understanding of crosscultural differences.

As expected, in both cultures respondents with related rather than separated self-types, regardless of their degree of individuation, perceived themselves as more related with their parents in actual, ideal, and, to some degree, expected terms. Again as would be expected, the impact of self-construal type was highest on actual and lowest on expected relatedness. Thus, it appears that respondents with related self-construals not only report more actual relatedness but also tend to idealize it and, to some degree, tend to perceive their parents as expecting more relatedness compared to those with separated self-construals. Furthermore, those effects did not vary either as a function of the individuational orientations or the cultural contexts of respondents, except for a multivariate trend for the separatedindividuated Americans to report relatively less relatedness than their Turkish counterparts; however, according to the univariate results, Turks and Americans with different self-construal types showed remarkably similar patterns of actual, ideal, and expected relatedness with parents, pointing to both cross-cultural similarities and within-culture variations.

Another consistent trend was implied by the associations between individualistic and collectivistic value orientations and relatedness measures. Within each society those students who tended to be more collectivistic (in terms of endorsing other-directed values) appeared to report more relatedness than those less so. However, in general, endorsing self-directed individualistic values appeared to be independent of relationality, except for a weak trend for individualistic orientation to predict being somewhat less related in the U.S.

\section{Gender-Related Differences}

As for gender-related findings, in both cultures, respondents appeared to be more related with their mothers than fathers. Furthermore, in terms of relatedness with mothers, women seem to perceive more actual, ideal, and expected relatedness than men do, whereas in terms of relatedness with fathers, male and female respondents do not seem to differ except that men tend to perceive more actual relatedness than women do. These findings are in line with the previously reported studies indicating women to be more interrelated in their relationships with parents and others (Chodorow, 1978; Frank, Avery \& Laman, 1988; Gilligan, 1982; Lykes, 1985; Youniss \& Ketterlinus, 1987). Similarly, women's higher endorsement of being related with their mothers seems to be consistent with other research reports indicating their close, intimate relationships and open communication with mothers relative to 
fathers (Frank, Avery, \& Laman, 1988; Fuligni, 1994; Hauser et al., 1987; Hunter \& Youniss, 1982; Youniss \& Ketterlinus, 1987). In fact, the mother-daughter bond has been considered to be prototypic of the related self (Jordan, 1997).

\section{STUDY 2: PERCEIVED RELATEDNESS WITH PARENTS AT THE UPPER AND LOWER SES IN TURKEY}

As noted in the general introduction, in this second study we aimed to explore SES-related differences in Turkey regarding the considered types of relatedness. Triandis $(1989 ; 1990 ; 1997)$ asserts that in all societies and cultures, the upper social classes are likely to be more individualistic than the lower social classes. Accordingly, there is socialization for obedience and duty, which emphasize belonging and fitting in lower SES settings, whereas in upper SES settings, there is socialization for independence and self-reliance, which emphasize being separate, unique and realizing inner attributes. In line with these conclusions, in the traditional sociocultural Turkish context, there appear to be 'fused and undifferentiated systems of relationships' (Fişek, 1984, p. 310). The ties with family members tend to be quite close and interdependent, but with increasing SES, Turkish people tend to express more individuated self-construals (Imamoğlu, 1987, 2003; Karakitapoğlu-Aygün, 2004) and individualistic values (Imamoğlu \& Karakitapoğlu-Aygün, 1999; Karakitapoğlu-Aygün \& Imamoğlu, 2002). However, those studies argued and demonstrated that these new preferences for individualism and autonomy among the upper SES people exist together with feelings of relatedness. For example, in studies of self-descriptions among Turkish university students and adults, who were mostly from middle-upper SES backgrounds, both relational and individualistic descriptions were found to be most descriptive of the self (Imamoğlu, 2002; Karakitapoğlu-Aygün, 2004).

Because they live in the same country, upper and lower SES adolescents may be expected to perceive similarly high degrees of expected relationality. However, since lower SES environments tend to be characterized by higher levels of interdependence and greater fusion among family members, these may influence children's perceptions of actual and ideal degrees of relatedness. Accordingly, we expected adolescents from lower SES backgrounds to report higher levels of ideal, and to some degree actual, relatedness with their parents than their upper SES counterparts. On the other hand, in congruence with the results of the first study, we expected differences in actual relatedness to be more pronounced for self-construal types than SES.

\section{Method}

\section{Participants}

A total of 353 (190 female, 163 male; mean age $15.44, S D=0.75$, range 14-18) high school students participated in the study. Of these, 186 ( 89 female, 97 male; mean age 15.25, $S D=0.78$, range 14-18) constituted the lower SES sample, and 167 (66 male, and 101 female; mean age 15.65, SD=0.66, range 14-17) the upper SES sample. Two public high schools from poorer sections of Ankara were chosen for the lower SES sample, and two private schools from the more prosperous areas for the upper SES sample. As expected, the samples were different in terms of parental education. In the lower SES sample, most of the mothers were primary school graduates $(56 \%)$ or had no schooling $(2 \%)$; and most of the fathers $(60 \%)$ were graduates of high school or junior high school; whereas in the upper SES sample, most of the fathers $(89 \%)$ and mothers $(69 \%)$ were university graduates or post-graduates. 


\section{Instruments and Procedure}

The same scales were used as in the first study. Students again completed them in their classrooms.

\section{Results}

To investigate SES and gender differences in relatedness, a 2 (SES: upper, lower) $\times 2$ (gender: male, female) $\times 2$ (parent: mother, father) $\times 3$ (type of relatedness: actual, ideal, expected) ANOVA with repeated measures on the last two variables was conducted. Furthermore, to explore across and withinSES differences in relatedness in terms of self-types and value orientations, two separate MANOVAs were conducted using actual, ideal, and expected relatedness as dependent variables, as explained below. In all follow-up analyses, Tukey technique was used for within-subject effects and univariate analysis of variance was used for between-subject effects. Moreover, in order to explore the role of individualistic and collectivistic values on relatedness, regression analyses were conducted, as in the first study.

\section{SES Differences in Relatedness}

The above-noted ANOVA results indicated all main effects to be significant, as shown in Table 6 . According to SES main effect, lower SES respondents $(M=6.86)$ showed more relatedness with their parents than the upper SES respondents $(M=6.30)$. In terms of type of relatedness, most relatedness was reported in the expected condition $(M=7.32)$, then ideal $(M=6.69)$, and least in the actual condition $(M=5.72)$, replicating the cross-cultural findings. Furthermore, participants reported more relatedness with their mothers $(M=6.69)$ than fathers $(M=6.46)$, as in the first study. These main effects were modified by significant interactions, as summarized in Table 6 and explained below.

First, SES by type of relatedness interaction was significant. As shown in Table 2, there were no differences between upper and lower SES respondents in the ratings of expected relatedness, but there were significant differences in actual and ideal ratings. As expected, lower SES students received higher scores in these types of relatedness than the upper SES students did.

Gender of the respondent by parent interaction was also found to be significant (Table 6). As shown in Table 3, there were no differences between male and female respondents in terms of relatedness with fathers; however, while male respondents reported equal levels of relatedness with their mothers and fathers, the female respondents displayed more relatedness with their mothers than their fathers, and more so than the males did.

Furthermore, gender of the respondent by type of relatedness interaction was significant. However, as can be seen in Table 3, follow-up analyses indicated only nonsignificant trends for female adolescents to display higher levels of ideal and expected relatedness than male ones $(p<0.06$ and 0.07 , respectively).

Finally, parent by type of relatedness interaction was significant (Table 6). Follow-up analyses indicated that there were no differences between relatedness with mothers and fathers in the ideal condition (Ms $=6.75$ and 6.64 for mothers and fathers, respectively), but mean scores of actual (5.82) and expected (7.50) relatedness with mothers were higher than the actual $(M=5.61)$ and expected $(M=7.10)$ relatedness with fathers $(p<0.01$ and 0.001 , respectively for actual and expected conditions).

In the analyses reported in the sections below, only the effects involving self-types or value orientations are considered. Since relatedness differences involving SES have already been reported, they are not repeated. 
Table 6. Significant ANOVA and MANOVA results involving SES data

\begin{tabular}{|c|c|c|c|c|}
\hline Source & $M S E$ & $d f$ & $F$ & $\eta^{2}$ \\
\hline \multicolumn{5}{|c|}{ Differences in relatedness across SES groups ${ }^{\mathrm{a}}$} \\
\hline SES & 9.32 & 1,332 & $16.35^{* * *}$ & 0.05 \\
\hline Relatedness Type & 1.67 & 2,664 & $253.51 * * *$ & 0.43 \\
\hline Parent & 2.20 & 1,332 & $11.43 * * *$ & 0.03 \\
\hline SES $\times$ Relatedness Type & 1.67 & 2,664 & $16.81 * * *$ & 0.05 \\
\hline Gender $\times$ Relatedness Type & 1.67 & 2,664 & $4.57 *$ & 0.01 \\
\hline Gender $\times$ Parent & 2.20 & 1,332 & $4.49 *$ & 0.01 \\
\hline Parent $\times$ Relatedness Type & 0.79 & 2,664 & $3.37 *$ & 0.01 \\
\hline \multicolumn{5}{|c|}{ Differences in relatedness of participants with different self-types ${ }^{b}$} \\
\hline Self-Type & & 9,781 & $11.07 * * *$ & 0.09 \\
\hline Actual Relatedness & 1.96 & 3,323 & $34.10 * * *$ & 0.24 \\
\hline Ideal Relatedness & 1.85 & 3,323 & $14.10 * * *$ & 0.12 \\
\hline Expected Relatedness & 1.52 & 3,323 & $7.48 * * *$ & 0.07 \\
\hline SES $\times$ Self-Type & & 9,781 & $3.36 * * *$ & 0.03 \\
\hline Actual Relatedness & 1.96 & 3,323 & 1.02 & 0.01 \\
\hline Ideal Relatedness & 1.85 & 3,323 & $4.70 * *$ & 0.04 \\
\hline Expected Relatedness & 1.52 & 3,323 & 0.61 & 0.01 \\
\hline \multicolumn{5}{|c|}{ Differences in relatedness of respondents with different value orientations ${ }^{c}$} \\
\hline Collectivist Orientation & & 3,305 & $10.24 * * *$ & 0.09 \\
\hline Actual Relatedness & 2.41 & 1,307 & $16.44 * * *$ & 0.05 \\
\hline Ideal Relatedness & 2.00 & 1,307 & $30.50 * * *$ & 0.09 \\
\hline Expected Relatedness & 1.41 & 1,307 & $12.86 * * *$ & 0.04 \\
\hline SES $\times$ Collectivist Orientation $\times$ Individualist Orientation & & 3,305 & $3.45 *$ & 0.03 \\
\hline Actual Relatedness & 2.41 & 1,307 & 0.28 & 0.00 \\
\hline Ideal Relatedness & 2.00 & 1,307 & 0.00 & 0.00 \\
\hline Expected Relatedness & 1.41 & 1,307 & $6.41 *$ & 0.02 \\
\hline
\end{tabular}

${ }^{\mathrm{a}} \mathrm{A} 2(\mathrm{SES}) \times 2($ Gender $) \times 2($ Parent $) \times 3$ (Relatedness type) ANOVA with repeated measures on the two last variables is involved.

${ }^{\mathrm{b}} \mathrm{A} 2$ (SES) $\times 4$ (Self type) MANOVA using relatedness types as dependent variables is involved. For SES effects involving relatedness types, see Table 2.

${ }^{\mathrm{c}}$ A $2(\mathrm{SES}) \times 2$ (Collectivist Value Orientation) $\times 2$ (Individualist Value Orientation) MANOVA using relatedness types as dependent variables is involved. For SES effects involving relatedness types, see Table 2.

${ }^{*} p<0.05 ; * * p<0.01 ; * * * p<0.001$.

\section{Differences in Relatedness of Respondents with Different Self Types}

According to the 2 (SES: upper, lower.) $\times 4$ (self type: separated-patterned, separated-individuated, related-patterned, related-individuated) MANOVA using actual, ideal, and expected relatedness as dependent variables, the multivariate self-type effect was found to be significant (see Table 6). As shown in Table 4, all the univariate effects were significant. Similar to the findings of the first study, students with related self-construals perceived greater relatedness with their parents as compared to the ones with separated construals in all types of relatedness except that separated-individuated and related-patterned groups did not differ in expected relatedness. Again replicating the findings of the first study, the impact of self-types was greatest on actual relatedness and least on expected relatedness with ideal relatedness being in between, as shown in Table 4.

Moreover, the multivariate SES by self-type interaction was found to be significant (Table 6). Univariate analyses indicated that this interaction was significant only for ideal relatedness type. Regardless of self-types, the lower SES participants reported greater ideal relatedness with their parents as compared to their upper SES counterparts, except for those with the related-patterned 
self-type, who were similarly related in both SES contexts $(M \mathrm{~s}=7.28$ and 7.09 for lower and upper SES, respectively). Furthermore in the ideal condition, respondents with separated self-construals appeared to be relatively less related at the upper SES compared to the lower SES $(M \mathrm{~s}=6.61$ and 7.16 at the lower SES for separated-patterned and separated-individuated types, respectively, while the respective means were 5.42 and 5.29 at the upper SES).

\section{Differences in Relatedness of Respondents with Different Value Orientations}

As shown in Table 5, in both SES groups collectivistic values positively predicted relatedness with parents in all types of relatedness, replicating the cross-cultural findings. Individualistic values did not predict relatedness in either SES group.

In parallel to the first study, a 2 (SES: lower, upper) $\times 2$ (individualist value orientation: low, high) $\times 2$ (collectivist value orientation: low, high) MANOVA was conducted using actual, ideal and expected relatedness as dependent variables. As shown in Table 6, the collectivist value orientation effect was significant for all types of relatedness. This collectivist value effect was independent of SES and the individualist value orientation except for a univariate interaction for expected relatedness involving both value types and SES (Table 6). According to this rather weak trend, the upper SES students who were high in both value orientations reported more expected relatedness, whereas the lower SES students who were low in both value orientations reported less expected relatedness than other students in their status groups.

\section{Discussion}

Turkish adolescents from different SES groups did not differ in their perceptions of expected relationality. That is, presumably because they live in the same society, adolescents from both SES groups perceived their parents as expecting similarly high relatedness. However, as expected, Turkish adolescents from the lower SES perceived their ideal and to some degree actual selves as more related or overlapping with their parents than those from upper SES did. This finding seems to be in line with the traditional dependency emphasis on parent-child relationships, which children seem to have idealized, and to some degree internalized, in these lower SES environments (Imamoğlu, 1987, 1991). Hence, results are consistent with the earlier reports that in lower SES environments where dependence of children to parents is emphasized (Imamoğlu, 1987), self-other boundaries appear to be fuzzier (Fişek, 1984).

In line with the results of the first study, differences involving self-construal types were largest in terms of actual relatedness; then in ideal relatedness; and least in expected relatedness. As expected, respondents with both related-individuated and related-patterned self-construals reported more actual and ideal relatedness than those with separated self-types (i.e., the separated individuated and separated-patterned types). On the other hand, for expected relatedness, the separated-individuated and related-patterned self-types appeared to be relatively less differentiated. These differences associated with self-construals did not vary as a function of SES except for ideal relatedness; i.e., respondents with the most integrated self-construal type (i.e., the related-patterned) perceived their ideal selves as similarly related in both SES groups, whereas those with the other self-types perceived their ideal selves as more related in the lower SES than in upper SES. Thus, in general, adolescents seem to idealize relatedness more in the lower SES than the upper SES, except for those having highly integrated self-types, which idealize relatedness in both status groups.

Again in consistency with the results of the cross-cultural study, collectivistic values seemed to predict relatedness with parents in both status groups. That is, regardless of SES, the more 
collectivistically oriented adolescents reported more ideal, actual and expected relatedness. Similar to SES, the collectivistic value orientation also seemed to have more impact on ideal relatedness than actual or expected relatedness. On the other hand, the individualistic value orientation appeared to be independent of relatedness. The general implications of these findings together with the cross-cultural ones are considered further in the section below.

As for gender-related results, regardless of SES, adolescents reported more actual and expected relatedness with mothers than fathers. On the other hand, when gender of the respondents is considered, female respondents from both SES reported more relatedness with mothers in comparison to both fathers and their male counterparts. Furthermore, regardless of SES, female respondents showed a trend to report more ideal and expected relatedness with parents than the male respondents did. Thus, gender-related findings were congruent with the earlier results and did not vary with SES.

\section{GENERAL DISCUSSION}

Present findings suggest several implications for our understanding of relatedness with parents. In this section, first differential impact of cross- (involving Turkey and U.S.A.) and within-culture differences (involving SES, self-types, and value orientations) on relatedness is considered. Secondly, the broader implications of the findings that question some tacit understandings regarding cultural differences are considered. Finally, some limitations and strengths of the present research are noted.

Results provided consistent trends for the differential impact of culture, SES, self-types, and value orientations on actual, ideal, and expected relatedness with parents. The impact of culture appeared to be mostly on perceived expectations of relatedness; and secondly, on ideal degree of relatedness conceived. Accordingly, Turkish respondents reported more expected and ideal relatedness than the Americans did, in line with the I-C literature, as noted in the Introduction. However, contrary to the I-C literature, Turks and Americans seemed to be rather similar in terms of their reports of actual relatedness with parents.

Though the cultural groups appeared to be quite similar in actual relatedness, they showed considerable within-culture variation involving self-types and value orientations, in almost all types of relatedness. Specifically, in both cultures respondents with more related self-types (regardless of their degree of individuation), as well as those with more other-directed, collectivistic value orientations (regardless of their degree of self-directed, individualistic value orientations) reported more actual, ideal, and to some degree expected relatedness compared to the respondents low in those self- and value-orientations. As would be expected, the impact of self-types seemed to be mostly on actual relatedness while that of value orientations appeared to be mostly on ideal relatedness. Since self-types, as measured by the BID scale, refer to actual differences in self-construals, it is not surprising that most of their impact was found to be on actual relatedness. As suggested by the BID model, past research indicated the interrelational self orientation to be predicted by parental loveacceptance (e.g., Imamoğlu, 2003). Hence, it appears that in actual relatedness with parents the immediate characteristics of the parent-child relationship may be more important than those of the broader culture. Present results further indicated that respondents with related self-types also reported more ideal and, to some degree, expected relatedness than the less related ones did. This latter finding suggests that the impact of self-construals may be quite pervasive, influencing not only one's ideals, but also perceptions of parental expectations.

On the other hand, because values tend to represent ideal end-states or means of achieving them (Rokeach, 1973), it would be understandable for the collectivistic value orientation to have most of its impact on ideal relatedness. In this regard, the finding that only the collectivistic value orientation 
predicted relatedness in both the U.S. and Turkey, societies labeled as individualistic and collectivistic, respectively, may provide partial support to the I-C conceptualization in terms of affirming the collectivism-relatedness link, but also questions its broader implications. On the other hand, the finding regarding the independence of relatedness from individualistic values may provide partial support to findings reporting the orthogonality of relatedness and I-C (e.g., Kashima et al., 1995; Oyserman et al., 2000). However, a weak trend was observed for the individualistic value orientation to predict being less related in the U.S., but not in Turkey. The latter finding is congruent with other research reports, which indicate that in the upper segments of the Turkish society relatedness and individuation tend to co-exist (Imamoğlu, 1987, 1998, 2003), in line with the BID model considered above. What seems to be suggested by the present findings is that individualistic value orientations, as well as individuational self-developmental orientations generally tend to be independent of relatedness, in congruence with earlier findings based on the BID model (Gezici \& Güvenç, 2003; Imamoğlu, 1998, 2002, 2003; Kurt, 2002). As for the slightly negative associations observed between individualistic values and relatedness in the U.S., other findings from our research project suggest that individualistic orientations might be somewhat negatively associated only with perceiving one's identity as distinct or related, but to be independent of emotional closeness in both Turkey and the U.S. (Imamoğlu \& Karakitapoğlu-Aygün, 2005).

Another within-culture variable, SES, appears to have an impact mostly on ideal relatedness, and to some degree on actual relatedness. The Turkish adolescents from the lower SES seem to perceive more actual relatedness, and more importantly, seem to idealize it more than those from the upper SES. In this regard, status- and collectivist value-related effects appear to be similar in terms of impacting mostly ideal relatedness. In fact, as asserted by Triandis $(1989,1990,1997)$, the lower SES Turkish respondents were found to endorse collectivist values more than their upper SES counterparts (Imamoğlu \& Karakitapoğlu-Aygün, 2004). On the other hand, unlike culture, which mostly impacted expected relatedness, SES did not seem to have a significant impact on expected relatedness. Presumably because they live in basically the same culture, adolescents perceived parents' expectations for relatedness to be similarly high in both SES groups. Those results are congruent with earlier findings from Turkey indicating that the upper and lower SES parents tend to expect similarly high levels of love and respect from their children (Imamoğlu, 1987).

In terms of gender, across cultural and SES groups women appear to be more related with their mothers in comparison to their fathers and male counterparts. The fact that the gender-related results were independent of culture and SES refers to the pervasiveness of relatedness among women across contexts, in consistency with the relevant gender literature, as noted before (e.g., Chodorow, 1978; Gilligan, 1982). However, the impact of gender-related effects was low in both studies. Thus, although consistent, gender differences in relatedness with parents appear to be rather weak across contexts.

\section{Broader Implications of the Findings}

Present findings may be considered to have some broader implications for our understanding of differences and similarities between cultures. First, when a significant cross-cultural difference is obtained, often we tend to interpret it as implying actual differences between cultures. However, present results caution that it may not necessarily be so. In fact, cultural differences may be more likely to reflect normative expectations and ideals rather than actual states.

Secondly, we often tend to consider cultures to be more homogeneous than they actually are (see also Bandura, 2001; Imamoğlu, 2003), and are likely to exaggerate differences between cultures and minimize those within, a phenomenon well-known in social cognition literature (Fiske \& Taylor, 1991). Accordingly, the tacit understanding of cultures often can be likened to that of a uniform worn 
by everyone belonging to a particular culture. However, present results suggest that one needs to be cautious of such trait-like tacit assumptions because far from being homogeneous, within-culture differences may be greater than those between cultures that are expected to be different, for instance, according to the I-C differentiation. When within-culture differences involving such important variables as self-types and value orientations are considered, then striking similarities may be observed between cultures. As will be remembered, our results involving self-types and value orientations seemed to show strikingly similar patterns across cultural contexts.

In sum, present findings are supportive of assertions that cultures often operate by normative claims, which may be developed into obligations (D'Andrade, 1997). However, because individuals living in a particular culture come to internalize such cultural claims through social interactions, they may vary in the degree to which they do internalize their culture's normative outlook. According to Geertz (1973a, 1973b), those social relations depend on the interaction of cultural, social structural, and personality systems, as noted in the Introduction. So rather than talking about culture abstractly as a property of some social groups, it is suggested that one should instead consider how cultural understandings are shared and vary among particular groups of people (Strauss \& Quinn, 1997). As Shore (1996) puts it, 'The remaining job is to delineate a more explicitly psychological picture of culture processes.' (p. 311). In a similar vein, Whiting (1976, cited in Smith \& Bond, 1998) notes that to be useful, the concept of culture needs to be unpacked (for instance, by identifying values, personalities, motivations, expectancies etc.), so that individuals from different or same groups can be located at some point on a universally valid psychological dimension. In the present research we aimed to take a step in that direction and tried to pinpoint the source of culture's impact on relatedness; and then by exploring the role of some within-culture variables, we tried to achieve a more integrated picture of the differential impact of cross- and within-culture differences on relatedness with parents.

\section{Limitations and Strengths of the Present Studies}

Before concluding, we need to note some limitations of our studies. First, an important limitation is that our cross-cultural data are limited to university students and SES-related Turkish data to high school students. Our results cannot be generalized to the Turkish and American societies, and lower and upper SES Turkish segments at large. Because university students across cultures tend to represent the better-educated, middle-upper SES groups (Freeman, 1997; Hofstede, 1980; Triandis, 1995), our cross-cultural results need to be viewed with this limitation in mind. It should also be remembered that the cross-cultural analyses were controlled for parental education. Furthermore, all data consist of students' self-reports and perceptions. For instance, when reference is made to 'actual' relatedness, what is meant is 'actual as perceived by' the respondent. Although using only adolescents' reports could be a limitation, we considered adolescents' own perceptions to be more important in this regard. Our studies are also limited in that only two cultures were involved. Future studies are needed to examine whether present findings can be generalized to other individualistic and collectivistic cultures. Another limitation is that relatedness was measured only in relation to parents. Other studies in the literature provide evidence that people relate differently to different in-groups such as relatives, friends, etc. (Göregenli, 1997; Imamoğlu et al. 1993; Rhee, Uleman, \& Lee, 1996; Uleman et al., 2000). These studies pointed to the variability in relational self, depending on the social context or target in-group. Then, it is clear that inclusion of others within the boundaries of self may vary with the type of in-groups depending on the social distance (Triandis, 1995). Thus, future studies may investigate whether present findings can be generalized to other in-group members.

In spite of the above-noted limitations, our studies had some strong aspects. One of the strengths of the present research was to consider both cross-cultural and within-culture variations in relatedness 
with parents. Another strength was to use the Higgins-based idea of exploring actual, ideal and expected types of relatedness. Results involving these different types of relatedness provided converging evidence for the differential impact of cross- and within-culture differences, and suggested that one needs to be rather cautious in how one interprets the implications of cultural differences.

\section{ACKNOWLEDGEMENT}

The present paper is based on an extended analysis of the data collected as part of a doctoral study conducted by the second author under the supervision of the first. We express our appreciation to Middle East Technical University and Turkish Academy of Sciences for the partial support they have provided.

\section{REFERENCES}

Ainsworth, M. D. S. (1972). Attachment and dependency: A comparison. In J. L. Gewirtz (Ed.), Attachment and dependency (pp. 97-137). Washington, DC: Winston \& Sons.

Aron, A., Aron, E. N., \& Smollan, D. (1992). Inclusion of other in the self scale and the structure of interpersonal closeness. Journal of Personality and Social Psychology, 63, 596-612.

Aron, A., Aron, E. N., Tudor, M., \& Nelson, G. (1991). Close relationships as including other in the self. Journal of Personality and Social Psychology, 60, 241-253.

Bandura, A. (2001). Social cognitive theory: An agentic perspective. Annual Review of Psychology, 52, 1-26.

Baumeister, R. F., \& Leary, M. R. (1995). The need to belong: Desire for interpersonal attachments as a fundamental human motivation. Psychological Bulletin, 117(3), 497-529.

Bellah, R. N., Madsen, R., Sullivan, W. M., Swidler, A., \& Tipton, S. M. (1985). Habits of the heart: Individualism and commitment in American life. New York: Harper \& Row.

Bowlby, J. (1988). A secure base: Clinical applications of attachment theory. London: Routledge.

Chodorow, N. (1978). The reproduction of mothering: Psychoanalysis and the sociology of gender. Berkeley: University of California Press.

Cross, S. E., Bacon, P. L., \& Morris, M. L. (2000). The relational-interdependent self-construal and relationships. Journal of Personality and Social Psychology, 78, 791-808.

Cross, S. E., \& Madson, L. (1997). Models of the self: Self-construals and gender. Psychological Bulletin, 122, $5-37$.

D'Andrade, R. G. (1997). Schemas and motivation. In R. G. D'Andrade, \& C. Strauss (Eds.), Human motives and cultural models (pp. 23-44). Cambridge: Cambridge University Press.

Fijneman, Y. A., Willemsen, M. E., \& Poortinga, Y. H. in cooperation with Erelcin, F. G., Georgas, J., Hui, H. C., Leung, K., \& Malpass, R. S. (1996). Individualism-collectivism: An empirical study of a conceptual issue. Journal of Cross-Cultural Psychology, 27, 381-401.

Fişek, G. O. (1984). Psychopathology and the Turkish family: A family systems theory analysis. In Ç. Kağıtçıbaşı (Ed.), Sex roles, family and community in Turkey. Bloomington: Indiana University.

Fiske, S. T., \& Taylor, S. E. (1991). Social cognition. New York: McGraw-Hill.

Frank, S. J., Avery, C. B., \& Laman, M. S. (1988). Young adult's perceptions of their relationships with their parents: Individual differences in connectedness, competence and emotional autonomy. Developmental Psychology, 24, 729-737.

Freeman, M. A. (1997). Demographic correlates of individualism and collectivism: A study of social values in Sri Lanka. Journal of Cross-Cultural Psychology, 28, 321-341.

Fuligni, A. J. (1994). The academic achievement and parent-child relationships of Chinese-American and European-American early adolescents. Unpublished Doctoral Dissertation, University of Michigan.

Gabriel, S., \& Gardner, W. L. (1999). Are there 'his' and 'hers' types of interdependence? The implications of gender differences in collective versus relational interdependence for affect, behavior, and cognition. Journal of Personality and Social Psychology, 77, 642-655. 
Gaines, J., Marelich, W. D., Bledsoe, K. L., Steers, W. N., Henderson, M. C., Granrose, C. S., Barajas, L., Hicks, D., Lyde, M., Takahashi, Y., Yum, N., Rios, D. I., Garcia, B. F., Farris, K. R., \& Page, M. S. (1997). Links between race/ethnicity and cultural values as mediated by racial/ethnic identity and moderated by gender. Journal of Personality and Social Psychology, 72(6), 1460-1476.

Geertz, C. (1973a). Religion as a cultural system. In The interpretation of cultures: Selected essays by Clifford Geertz (pp. 87-125). New York: Basic.

Geertz, C. (1973b). Ritual and social change: A Javanese example. In The interpretation of cultures: Selected essays by Clifford Geertz (pp. 142-169). New York: Basic.

Georgas, J., Mylonas, K., Bafiti, T., Poortinga, Y. H., Christakopoulou, S., Kağıtçıbaşı, C., Kwak, K., Ataca, B., Berry, J., Orung, S., Sunar, D., Charalambous, N., Goodwin, R., Wang, Z., Angleitner, A., Stepanikova, I., Pick, S., Givaudan, M., Zhuravliova-Gionis, I., Konantambigi, R., Gelfand, M. J., Marinova, V., McBride-Chang, C., \& Kodic, Y. (2001). Functional relationships in the nuclear and extended family: A 16-culture study. International Journal of Psychology, 36, 289-300.

Gezici, M., \& Güvenç, G. (2003). Çalışan kadınların ve ev kadınlarının benlik algısı ve benlik kurgusu açısından karşılaştırılması (Self-perception and self-construals of women in relation to employment and domestic status). Turkish Journal of Psychology, 18, 1-17.

Gilligan, C. (1982). In a different voice: Psychological theory and women's development. Cambridge, MA: Harvard University Press.

Göregenli, M. (1997). Individualist and collectivist tendencies in a Turkish sample. Journal of Cross-Cultural Psychology, 28, 787-794.

Güler, A. (2004). Relationship between self-construals and future-time orientations. Unpublished M. S. Thesis, Middle East Technical University.

Hauser, S. T., Book, B. K., Houlihan, J., Powers, S., Weiss-Perry, B., Follansbee, D., Jacobson, A. M., \& Noam, G. G. (1987). Sex differences within the family: Studies of adolescent and parent-family interactions. Journal of Youth and Adolescence, 16, 199-220.

Higgins, E. T. (1987). Self-discrepancy: A theory relating self and affect. Psychological Review, 94, 319340.

Hofstede, G. (1980). Culture's consequences: International differences in work related values. Beverly Hills, CA: Sage.

Hunter, F. T., \& Youniss, J. (1982). Changes in functions of three relations during adolescence. Developmental Psychology, 18, 806-811.

Imamoğlu, E. O. (1987). An interdependence model of human development. In Ç. Kağıtçıbaşı (Ed.), Growth and progress in cross-cultural psychology (pp. 138-145). Lisse, The Netherlands: Swets and Zeitlinger.

Imamoğlu, E. O. (1991). Çocuğun aile içinde yetişme ortami ve toplumsallaşmasi (Socialization of the child in the family context). Türkiye Aile Ansiklopedisi (Vol. 1, pp. 236-240). Ankara: Türkiye Yazarlar Birliği Vakfi.

Imamoğlu, E. O. (1995). Değişim sürecinde aile: Evlilik ilişkileri, bireysel gelişim ve demokratik değerler (Family in transition: Marital relations, individual development, and democratic values). 1994 Aile Kurultayl, (pp. 35-51). Ankara, Turkey: Aile Araştırma Kurumu.

Imamoğlu, E. O. (1998). Individualism and collectivism in a model and scale of balanced differentiation and integration. Journal of Psychology, 132, 95-105.

Imamoğlu, E. O. (2002). Doğu-Bati kavşağında benlik: Dengeli ayrışma-bütünleşme modeli (Self at East-West crossroads: The balanced integration-differentiation model). Invited speech, the 12th Turkish Psychology Congress, Ankara.

Imamoğlu, E. O. (2003). Individuation and relatedness: Not opposing, but distinct and complementary. Genetic, Social, and General Psychology Monographs, 129, 367-402.

Imamoğlu, E. O. \& Imamoğlu, V. (1992). Life situations and attitudes of the Turkish elderly toward institutional living within a cross-cultural perspective. Journal of Gerontology: Psychological Sciences, 47(2), 102-108.

Imamoğlu, E. O., \& Imamoğlu, V. (1996). Insan, evi ve çevresi (Individuals, their homes, and environments). Ankara: Başbakanlık Toplu Konut Idaresi Yayını.

Imamoğlu, E. O., \& Karakitapoğlu-Aygün, Z. (1999). 1970lerden 1990lara değerler: Üniversite düzeyinde gözlenen zaman, kuşak ve cinsiyet farklılıkları (Value preferences from 1970s to 1990s: Cohort, generation and gender differences at a Turkish university). Turkish Journal of Psychology, 14(44), 1-22.

Imamoğlu, E. O., \& Karakitapoğlu-Aygün, Z. (2004). Self-construals and values across different cultural and socioeconomic contexts. Genetic, Social and General Psychology Monographs, 130(4), 277-306.

Imamoğlu, E. O., \& Karakitapoğlu-Aygün, Z. (2005). Relatedness of identities and emotional closeness with parents across and within cultures. Manuscript under review. 
Imamoğlu, E. O., Küller, R., Imamoğlu, V., \& Küller, M. (1993). The social psychological worlds of Swedes and Turks in and around retirement. Journal of Cross-Cultural Psychology, 24, 26-41.

Jordan, J. V. (1997). The relational model is a source of empowerment for women. In M. R. Walsh (Ed.), Women, men and gender: Ongoing debates (pp. 373-379). New Haven: Yale University Press.

Karakitapoğlu-Aygün, Z. (2004). Self, identity, and emotional well-being among Turkish university students. The Journal of Psychology, 138, 457-478.

Karakitapoğlu-Aygün, Z., \& Imamoğlu, E. O. (2002). Value domains of Turkish adults and university students. The Journal of Social Psychology, 142, 333-351.

Kashima, Y., Kim, U., Gelfand, M. J., Yamaguchi, K. Y., Choi, S. C., \& Yuki, M. (1995). Culture, gender and self: A perspective from individualism-collectivism research. Journal of Personality and Social Psychology, 69, 925-937.

Kurt, A. (2002). Autonomy and relatedness: A comparison of Canadians and Turks. Paper presented at the Annual Convention of Canadian Psychological Association, Vancouver, BC.

Lykes, M. B. (1985). Gender and individualistic versus collectivist bases for notions about the self. Journal of Personality, 53, 357-383.

Markus, H. R., \& Kitayama, S. (1991). Culture and the self: Implications for cognition, emotion and motivation. Psychological Review, 98, 224-253.

Mellor, S. (1989). Gender differences in identity formation as a function of self-other relations. Journal of Youth and Adolescence, 18, 361-375.

Olver, R. R., Aries, E., \& Batgos, J. (1989). Self-other differentiation and the mother-child relationship: The effects of sex and birth order. Journal of Genetic Psychology, 150, 311-321.

Oyserman, D., Coon, H. M., Kemmelmeier, M. (2002). Rethinking individualism and collectivism: Evaluation of theoretical assumptions and meta-analyses. Psychological Bulletin, 128, 3-72.

Rhee, E., Uleman, J. S., \& Lee, H. K. (1996). Variations in collectivism, and individualism by in-group and culture: Confirmatory factor analyses. Journal of Personality and Social Psychology, 71, 1037-1054.

Rokeach, M. (1973). The nature of human values. New York: Free Press.

Rothbaum, F., Pott, M., Azuma, H., Miyake, K., \& Weisz, J. (2000). The development of close relationships in Japan and the United States: Paths of symbiotic harmony and generative tension. Child Development, 71, $1121-1142$.

Sampson, E. E. (1988). The debate on individualism: Indigenous psychologies of the individual and their role in individual and societal functioning. American Psychologist, 43, 15-22.

Schwartz, S. H. (1992). Universals in the content and structure of values. In M. Zanna (Ed.), Advances in experimental psychology (Vol. 25, pp. 1-62). New York: Academic Press.

Schwartz, S. H., Melech, G., Lehmann, A., Burgess, S., Harris, M., \& Owens, V. (2001). Extending the crosscultural validity of the theory of basic human values with a different method of measurement. Journal of CrossCultural Psychology, 32, 519-542.

Shore, B. (1996). Culture in mind: Cognition, culture, and the problem of meaning. Oxford: Oxford University Press.

Sinha, D., \& Tripathi, R. C. (1994). Individualism in a collectivist culture: A case of coexistence of opposites. In U. Kim, H. C. Triandis, Ç. Kağıtçıbaşi, S. C. Choi, \& G. Yoon (Eds.), Individualism and collectivism: Theory, method and application (pp. 123-136). Thousand Oaks, CA: Sage.

Smith, P. B., \& Bond, M. H. (1998). Social psychology across cultures. London: Prentice Hall Europe.

Strauss, C., \& Quinn, N. (1997). A cognitive theory of cultural meaning. Cambridge: Cambridge University Press.

Sunar, D. (1999). Culture and gender influences on self-concept and the bases of self-esteem: Four Turkish studies. In W. J. Lonner (Ed.), Merging past, present and future in cross-cultural psychology: Selected papers from the 14th International Congress of the International Association for Cross-Cultural Psychology (pp. 387395). Lisse, Netherlands: Swets \& Zeitlinger.

Triandis, H. C. (1989). The self and social behavior in differing cultural contexts. Psychological Review, 96, 506520.

Triandis, H. C. (1990). Cross-cultural studies of individualism and collectivism. In J. Berman (Ed.), Nebraska symposium on motivation, 1989 (pp. 41-133). Lincoln: University of Nebraska Press.

Triandis, H. C. (1995). Individualism and collectivism. Boulder: Westview.

Triandis, H. C. (1997). Cross-cultural perspectives on personality. In R. Hogan (Ed.), Handbook of personality psychology (pp. 439-464). San Diego, CA: Academic Press.

Triandis, H. C., Bontempo, R., Villareal, M. J., Asai, M., \& Lucca, N. (1988). Individualism and collectivism: Cross-cultural perspectives on self-in-group relationships. Journal of Personality and Social Psychology, 54, 323-338. 
Uleman, J., Rhee, E., Bardoliwalla, N., Semin, G., \& Toyama, M. (2000). The relational self: Closeness to ingroups depends on who they are, culture and the type of closeness. Asian Journal of Social Psychology, 3, $1-17$.

Van den Heuvel, K., \& Poortinga, Y. H. (1999). Resource allocation by Greek and Dutch students: A test of three models. International Journal of Psychology, 34, 1-13.

Van Ijzendoorn, M. H., \& Sagi, A. (1999). Cross-cultural patterns of attachment: Universal and contextual dimensions. In J. Cassidy, \& P. R. Shaver (Eds.), Handbook of attachment: Theory, research, and clinical applications (pp. 434-465). New York: Guilford Press.

Youniss, J., \& Ketterlinus, R. D. (1987). Communication and connectedness in mother and father-adolescent relationships. Journal of Youth and Adolescence, 16, 265-280. 